\title{
Qualitative Determination of Human Chorionic Gonadotropin in Vaginal Washings for the Early Diagnosis of Premature Rupture of Fetal Membranes
}

\section{Determinação qualitativa de gonadotrofina coriônica humana no lavado vaginal para o diagnóstico precoce de ruptura prematura de membranas fetais}

\begin{abstract}
Camila Buziquia Dartibale ${ }^{1}$ Nelson Shozo Uchimura ${ }^{1}$ Luiz Nery ${ }^{1}$ Angelita Polato Schumeish ${ }^{2}$
\end{abstract} Liza Yurie Teruya Uchimura ${ }^{3}$ Rosangela Getirana Santana ${ }^{4}$ Taqueco Teruya Uchimura ${ }^{4}$

\footnotetext{
${ }^{1}$ Department of Medicine, Universidade Estadual de Maringá - UEM, Maringá, Paraná, PR, Brazil

${ }^{2}$ Laboratory Division, Hospital Universitário Regional de Maringá, Universidade Estadual de Maringá - UEM, Maringá, Paraná, PR, Brazil

3 Departament of Preventive Medicine, Faculdade de Medicina,

Universidade de São Paulo (DMP/FMUSP), São Paulo, São Paulo, SP, Brazil

${ }^{4}$ Departament of Statistics, Universidade Estadual de Maringá - UEM,

Maringá, Paraná, PR, Brazil
}

Address for correspondence Camila Buziquia Dartibale, MD, Departamento de Medicina, Universidade Estadual de Maringá - UEM, Av. Mandacarú, 1590-Parque das Laranjeiras, 87083-240-Maringá, PR, Brazil (e-mail: camila_dartibale@hotmail.com).

Rev Bras Ginecol Obstet 2017;39:317-321.

Abstract
Keywords
- human chorionic
gonadotropin
- $\beta$ subunit
- premature rupture of
fetal membranes
- diagnosis
- obstetrics
- pregnancy
complications

Purpose This study aimed to evaluate and validate the qualitative human chorionic gonadotropin $\beta$ subunit ( $\beta$-hCG) test of the vaginal fluid washings of pregnant women with premature rupture of fetal membranes (PROM).

Methods Cross-sectional study of pregnant women between gestational weeks 24 and 39 who underwent consultations in one of our institutions. They were divided into two groups: group A (pregnant women clinically diagnosed with PROM) and group B (pregnant women without loss of amniotic liquid). The patients were subjected to a vaginal fluid washing with $3 \mathrm{~mL}$ of saline solution, which was aspirated subsequently with the same syringe. The solution was immediately sent to the laboratory to perform the vaginal $\beta$-hCG test with cut-off points of $10 \mathrm{mIU} / \mathrm{mL}$ ( $\beta$-hCG-10) and/or $25 \mathrm{mIU} / \mathrm{mL}$ ( $\beta$-hCG-25).

Results The $\beta$-hCG-10 test of the vaginal secretion was performed in 128 cases. The chi-squared test with Yates' correction showed a statistically significant difference between the 2 groups $(p=0.0225)$. The sensibility, specificity, positive predictive value (PPV), negative predictive value (NPV), and accuracy parameters were $77.1 \%$, $43.6 \%, 52.3 \%$; $70.4 \%$; and $58.6 \%$ respectively. The $\beta$-hCG- 25 test of the vaginal washing received

November 3, 2016 accepted

April 4, 2017

published online

June 16, 2017
DOI https://doi.org/

10.1055/s-0037-1603939.

ISSN $0100-7203$.
Copyright $\odot 2017$ by Thieme Revinter

Publicações Ltda, Rio de Janeiro, Brazil
License terms

(ㄷ) (i) $\ominus$ (\$) 


\section{Resumo}

\author{
Palavras-chave \\ - gonadotrofina \\ coriônica humana \\ - subunidade $\beta$ \\ - ruptura prematura \\ de membranas \\ fetais \\ - diagnóstico \\ - obstetrícia \\ - complicações na \\ gravidez
}

was performed in 49 cases. The analysis by Fisher's exact test showed a statistically significant difference between the groups $(p=0.0175)$. The sensibility, specificity, PPV, NPV, and accuracy parameters were $44.4 \%, 87.1 \%, 66.6 \% ; 72.9 \%$; and $71.4 \%$ respectively.

Conclusions The $\beta$-hCG-25 test showed better accuracy for the diagnosis of PROM, and can corroborate the early diagnosis of PROM because it is a simple and quick exam.

Objetivo Este estudo objetivou validar o exame qualitativo da subunidade $\beta$ da gonadotrofina coriônica humana ( $\beta$-hCG) em lavado vaginal de gestantes com ruptura prematura de membranas (RPM) fetais.

Métodos Estudo transversal de gestantes com 24 a 39 semanas atendidas em um hospital de Maringá divididas em 2 grupos: grupo A (clinicamente diagnosticadas com RPM) e grupo B (gestantes sem perda de liquido amniótico). As pacientes foram submetidas a lavado vaginal com $3 \mathrm{~mL}$ de soro fisiológico, que logo em seguida foi aspirado de volta na mesma seringa e imediatamente enviado ao laboratório para a realização do exame de $\beta$-hCG vaginal com pontos de corte de $10 \mathrm{mIU} / \mathrm{mL}$ ( $\beta$-hCG-10) e/ ou $25 \mathrm{mIU} / \mathrm{mL}$ ( $\beta$-hCG-25).

Resultados $O$ teste de $\beta$-hCG-10 na secreção vaginal foi realizado em 128 casos, e o teste do qui-quadrado com correção de Yates mostrou diferença significante entre os dois grupos $(p=0,0225)$. Os parâmetros de sensibilidade, especificidade, valor preditivo positivo (VPP), valor preditivo negativo (VPN) e acurácia foram respectivamente $77,1 \% ; 43,6 \% ; 52,3 \% ; 70,4 \%$; e $58,6 \%$. O teste de $\beta$-hCG-25 na secreção vaginal foi realizado em 49 casos, e a análise pelo teste exato de Fisher mostrou diferença significativa entre os grupos ( $p=0,0175)$. Os parâmetros de sensibilidade, especificidade, VPP, VPN e acurácia foram respectivamente $44,4 \% ; 87,1 \%$; $66,6 \% ; 72,9 \%$; e $71,4 \%$.

Conclusões O $\beta$-hCG-25 apresentou melhor acurácia para o diagnóstico de RPM, e pode corroborar o diagnóstico precoce de RPM por se tratar de um exame simples e rápido.

\section{Introduction}

Premature rupture of fetal membranes (PROM) is the rupture of the chorionic membranes prior to labor at any time during the pregnancy. Its prevalence ranges from $8-19.53 \%$ of term pregnancies, and from $2-25 \%$ of all pregnancies. Traditionally, the diagnosis of PROM involves vaginal discharge history of amniotic fluid verified at speculum examination with the ferning test in the microscopic exam and the nitrazine test of the vaginal discharge. ${ }^{1,2}$ The early and accurate diagnosis of PROM is very important to start the correct treatment, enabling good perinatal outcomes and minimizing complications rates and clinical damage. ${ }^{2,3}$

Infection is the most common complication of PROM, and the incidence of this damage is more frequent the longer is the latency period of delay in the diagnosis. ${ }^{4}$ Moreover, other complications include prolonged and preterm labor, cord accident, neonatal sepsis, respiratory distress syndrome, and increase in perinatal mortality especially associated with prematurity. ${ }^{1,5,6}$

The best method to confirm PROM is a visible leakage of amniotic fluid from the cervix, although this method is associated with $12-30 \%$ of false negative results. The sensi- bility of the ferning and nitrazine tests ranges from $42-81 \%{ }^{7}$ A long latency period is more connected to a wrong diagnosis due to the paucity of amniotic fluid in the posterior fornix. The same difficulty occurs with the nitrazine test: after 48 hours of latency, this test shows $9.4 \%$ of false negative results. Furthermore, cervicitis, vaginitis, the presence of alkaline urine in the vaginal fluid, semen, blood and antiseptics are associated to $17.4 \%$ of false positive results. ${ }^{8}$ The ferning test also is affected by the same factors: the false negative rate ranges from $13-30 \%$, and the false positive rate ranges from $5-30 \%{ }^{1}$

Thus, when the loss of amniotic fluid is clear, the diagnosis is easy. On the other hand, it becomes difficult or impossible in long latency periods or when the rupture was discreet and high, which leads to the discharge of a scarce amount of amniotic fluid. Complex cases lead to false positive results that, in turn, can lead to wrong, high-cost treatments, like hospitalization and labor induction. However, the absence of a correct diagnosis is harmful, because the patient may not receive the appropriate assistance, such as antibiotic and corticosteroid therapies. ${ }^{1,2,4,9}$ Therefore, new biochemical methods for early and accurate diagnoses are necessary. ${ }^{10}$ 
Due to the absence of a golden standard method for the diagnosis of PROM, many studies have been performed to find an easy test that is definitive, noninvasive, and able to improve the diagnosis of PROM. ${ }^{2}$ Current studies emphasize research on biochemical agents found at high levels in the amniotic fluid: prolactin, $\alpha$-fetoprotein, insulin-like growth factor, fetal fibronectin, urea, lactate, placental alpha microglobulin-1, diamine oxidase, human chorionic gonadotropin (hCG), and creatine. ${ }^{2-4,8,9,11-14}$

Most of these tests are not popular because they have high costs and complexity. ${ }^{2}$ Out of all biochemical markers studied, we highlight the hCG $\beta$ subunit ( $\beta$-hCG). The $\beta$-hCG test has an easy determination, fast result, low cost, and many studies suggest high sensibility and specificity for the diagnosis of PROM.

The hCG is a glycoprotein produced by trophoblastic tissue, and it is present in varying levels in the blood, urine and amniotic fluid. During pregnancy, the level of hCG in the blood increases progressively until it reaches $54,000 \mathrm{mUI} / \mathrm{mL}$ in 8 to 12 weeks of gestation. Subsequently, there is a decrease in the levels of hCG in the blood to $12,000 \mathrm{mUI} / \mathrm{mL}$ around 20 gestational weeks. The hCG is present in the amniotic fluid, in the maternal urine, and its concentration ranges from 2,000 to $70,000 \mathrm{mUI} / \mathrm{mL}$. This marker is released by cervical glands that are responsible for its presence in the vaginal fluid. However, there is little information about the level of $\beta$-hCG in the vaginal fluid and its fluctuation between the three pregnancy trimesters. ${ }^{4,8,10}$

Quantitative analysis of the $\beta$-hCG is expensive and takes time, but the qualitative analysis is simple, fast, inexpensive, and can be used in the diagnosis of PROM. Therefore, it is possible that the pregnancy test over the threshold to the $\beta$-hCG level in the vaginal discharge in a normal pregnancy. ${ }^{8,11}$

Given the aforementioned data, the present study advocates the qualitative analysis of the hCG with cut-off points of $10 \mathrm{mIU} / \mathrm{mL}(\beta-\mathrm{hCG}-10)$ and $25 \mathrm{mIU} / \mathrm{mL}(\beta-\mathrm{hCG}-25)$ in the vaginal fluid washings of pregnancies with PROM. In order to do this, we used the calculations of sensibility, specificity, positive predictive value (PPV), negative predictive value (NPV), accuracy, likelihood ratio for a positive test result $(\mathrm{LR}+)$, and likelihood ratio for a negative test result (LR-). This analysis aims to launch the development and validation of new technology in the early diagnosis of PROM.

\section{Methods}

A cross-sectional, prospective and analytic study of pregnant women between gestational weeks 24 and 39 attending a university hospital in the state of Paraná, Brazil. The sample population was divided into two groups: group A (pregnant women clinically diagnosed with PROM) and group B (pregnant women without loss of amniotic liquid). The study's exclusion criteria were: presence of uterine dynamic; fetal distress; and presence of blood in the vaginal fluid. The diagnosis of PROM was made after the amniotic fluid flow was observed through the hole cervical during the vaginal speculum exam. Moreover, the diagnosis was complemented by the results of the nitrazine test, with a $\mathrm{pH} \geq 6$, and the fern test of the vaginal fluid. The patients were subjected to a vaginal fluid washing with $3 \mathrm{~mL}$ of saline solution, which was aspirated subsequently with the same syringe and sent directly to the laboratory. The remaining solution was centrifuged (1,500 rpm), and it was qualitatively tested for the presence of $\beta$-hCG-25 and $\beta$-hCG-10.

The data analysis was performed using the chi-squared test with Yates' correction and Fisher's exact test. For the statistical analysis, a 95\% confidence interval (95\%CI) was considered, and values of $p<0.05$ were considered statistically significant. First, the data were tabulated using the Microsoft Excel software (Microsoft Corporation, Redmond, WA, US), and the data were analyzed using the Epi Info software, version 3.5.2 (Centers for Disease Control and Prevention, Atlanta, GA, US), and the Statistical Analysis System (SAS), version 9.4 (SAS Institute, Cary, NC, US).

The study was submitted to the Ethics Committee of one of our institutions and approved under protocol number 515/ 2009. All participants signed a free and informed consent form (FICF), and the research followed the Helsinki Declaration, which was reviewed in 2008.

\section{Results}

The analysis was performed on 177 pregnant women. The B-hCG-10 test was performed on 128 (72.3\%) pregnant women, 57 (44.6\%) of which belonged to group A (those with PROM), and 71 to group B (those without loss of amniotic liquid). The $\beta$-hCG-25 test was performed on 49 (27.7\%) pregnant women, 18 (36.7\%) of which belonged to group A, and 31 (63.3\%) to group $B$.

The $\beta$-HCG-10 test of the vaginal fluid was positive in 44 (34.4\%) women in group A, and in 40 (31.2\%) women in group $B$; therefore, there were $13(10.2 \%)$ cases of false negative results. The statistical analysis using the chi-squared test with Yates' correction showed a statistically significant difference between the groups $(p=0.0225)$ for the $\beta$-HCG10 test ( $\mathbf{- T a b l e ~} \mathbf{1}$ ).

The $\beta$-hCG-10 vaginal test had $77.1 \%$ of sensitivity, $43.6 \%$ of specificity, 52.3\% (44/84) of PPV, 70.4\% (31/44) of NPV, and $58.6 \%(75 / 128)$ of accuracy in the diagnosis of PROM. The likelihood ratio for a positive test result ( $\mathrm{LR}+$ ) was 1.37 , and the likelihood ratio for a negative test result (LR-) was 0.50 .

Table 1 Distribution of the pregnant women in group A (PROM) and group $B$ (control) according to the $\beta$-hCG-10 test of vaginal washes. Maringá, Paraná, Brazil, 2015

\begin{tabular}{|l|l|l|l|l|l|l|}
\hline B-hCG-10 test & \multicolumn{2}{|l|}{$\begin{array}{l}\text { Group A } \\
\text { (PROM) }\end{array}$} & \multicolumn{2}{l|}{$\begin{array}{l}\text { Group B } \\
\text { (control) }\end{array}$} & \multicolumn{2}{l|}{ TOTAL } \\
\cline { 2 - 7 } & $\mathrm{N}$ & $\%$ & $\mathrm{~N}$ & $\%$ & $\mathrm{~N}$ & $\%$ \\
\hline Positive & 44 & 34.4 & 40 & 31.2 & 84 & 65.6 \\
\hline Negative & 13 & 10.2 & 31 & 24.2 & 44 & 34.4 \\
\hline TOTAL & 57 & 44.6 & 71 & 55.4 & 128 & 100 \\
\hline
\end{tabular}

Abbreviations: $\beta$-hCG-10, human chorionic gonadotropin $\beta$ subunit test with a cut-off point of $10 \mathrm{mlU} / \mathrm{mL}$; PROM, premature rupture of fetal membranes. Notes: Chi-squared test $\left(x^{2}\right)=5.21 ; p=0.0225$; Yates' correction for continuity; odds ratio $(O R)=2.62(1.13-6.15)$. 
Table 2 Distribution of the pregnant women in group A (PROM) and group $B$ (control) according to the $\beta$-hCG 25 test of vaginal washes. Maringá, Paraná, Brazil, 2015

\begin{tabular}{|c|l|l|l|l|l|l|}
\hline B-hCG 25 & \multicolumn{2}{l|}{$\begin{array}{l}\text { Group A } \\
\text { (PROM) }\end{array}$} & \multicolumn{2}{l|}{$\begin{array}{l}\text { Group B } \\
\text { (control) }\end{array}$} & \multicolumn{2}{l|}{ Total } \\
\hline & $\mathrm{N}$ & $\%$ & $\mathrm{~N}$ & $\%$ & $\mathrm{~N}$ & $\%$ \\
\hline Positive & 8 & 16.3 & 4 & 8.2 & 12 & 24.5 \\
\hline Negative & 10 & 20.4 & 27 & 55.1 & 37 & 75.5 \\
\hline TOTAL & 18 & 36.7 & 31 & 63.3 & 49 & 100 \\
\hline
\end{tabular}

Abbreviations: $\beta$-hCG-25, human chorionic gonadotropin $\beta$ subunit test with a cut-off point of $25 \mathrm{mlU} / \mathrm{mL}$; PROM, premature rupture of fetal membranes.

Notes: Chi-squared test $\left(X^{2}\right)=4.54 ; p=0.0175$; Fisher's exact test; odds ratio $(O R)=5.40(1.11-28.10)$.

The $\beta$-hCG-25 test of the vaginal fluid was positive in 8 (16.3\%) cases in group A, and in $4(8.2 \%)$ cases in group B, with $10(20.4 \%)$ cases of false negatives. The statistical analysis using Fisher's exact test showed a statistically significant difference between the groups for the $\beta$-hCG-25 vaginal test $(p=0.0175)$ (-Table 2 ).

The $\beta$-hCG-25 vaginal test had $44.4 \%$ of sensitivity, $87.1 \%$ of specificity, 66.6\% (8/12) of PPV, 72.9\% (27/37) of NPV and an accuracy of $71.4 \%$ in the diagnosis of PROM. The LR+ was of 3.41 and the LR- was of 0.63 .

\section{Discussion}

The qualitative hCG test for the diagnosis of PROM has shown to be a better method than the traditional diagnosis methods like the ferning and nitrazine $(\mathrm{pH})$ tests and the speculum exam. The hCG measurement is not modified by the same factors as the ferning and nitrazine tests. In fact, the speculum exam is of no help when it is performed after a long latency period, while a high hCG concentration can be measured in the vaginal fluid 24 hours after the PROM. ${ }^{1}$

The determination of the amount of $\beta$-hCG-25 in the vaginal fluid can be used as a good method for the diagnosis of PROM, and it had an accuracy of $71.4 \%$ in the present study. In the literature, this method was reported to have an accuracy of $87 \%{ }^{8}$

The $\beta$-hCG-25 test had low sensitivity (44.4\%), probably due to the fewer PROM samples used in the present study. This hypothesis is supported by other studies with better results, which used the same cut-off point, but had larger samples. $8,9,12$ On the other hand, this test provided a good amount of specificity (87.1\%), which shows its good diagnosis power. Moreover, we achieved specificity rates that were higher than those of many previous studies, which reported specificity rates of $68 \%, 84 \%, 86 \%$, for example. ${ }^{13-15}$

In the present study, the $\beta$-hCG-10 and $\beta$-hCG-25 tests provided NPVs of $70.4 \%$ and $72.9 \%$ respectively. These results were better than the NPV of another study that used a bigger cut-off point (100 mUI/mL). ${ }^{4}$

Likelihood ratio is the ratio between the probability of a result at a diagnosis test in people with a disease and the probability of getting the same result in healthy people. So, for the $\beta$-hCG-10 test, the LR+ of 1.37 is the chance to find a positive result in people with PROM (true positive), and it is similar to finding a positive result in healthy people (false positive). The LR- of 0.5 means that the chance to find a false negative result relative to a true negative result is of 50:100, or that the chance of a negative outcome being true for this cut-off point relative to a false negative result is of 2.00 . A negative result for this cut-off point can help us reasonably distinguish a healthy person from someone with PROM.

For the $\beta$-hCG-25 test, the LR + of 3.41 means that, for this cut-off point, the chance that the test result is a true positive is 3.41 times higher than the chance of the test result being a false positive. In this case, a positive result can help us distinguish those with PROM from the healthy subjects. The LR- of 0.63 means that the chance the negative test result is false is of 63:100; in other words, the chance a negative test result is true for this cut-off point is 1.58 times higher than the chance a negative test result is false. The accuracy of the $\beta$-hCG-10 test was of 0.58 , and for the $\beta$-hCG-25 test, it was of 0.71 .

When the two cut-off points of the present study are compared, it is possible to notice that the $\beta$-hCG-25 test has a greater discriminatory power for PROM than the $\beta$-hCG-10 test.

Many studies discuss the ideal cut-off point for the hCG test for the diagnosis of PROM. ${ }^{16}$ In our review, the major cutoff point studied was of $100 \mathrm{mUI} / \mathrm{mL}$, and it provided a sensibility of $71.2 \%$, a specificity of $100 \%$, a PPV of $100 \%$, and an NPV of 65.1\%; even though there was a high specificity with this cut-off point, it showed lower sensibility. ${ }^{4}$ A cut-off point of $39.8 \mathrm{mUI} / \mathrm{mL}$ was also studied, and all parameters were higher than $90 \%$, so the literature suggests that this is a good value to be considered. ${ }^{16}$ Researchers had who used a cut-off point $\leq 25 \mathrm{mUI} / \mathrm{mL}$ also achieved sensibility and specificity rates higher than than $90 \%$, which suggest this can be an appropriate value. ${ }^{1,12,17,18}$

During pregnancy, the cervical glands release hCG in the vaginal fluid, but the concentration remains lower than 10 $\mathrm{mUI} / \mathrm{mL}$ after the 20 th gestational week, ${ }^{1}$ which supports the possibility of performing the $\beta$-hCG qualitative test with a cut-off point of $10 \mathrm{mUI} / \mathrm{mL}$. However, in this study, the $\beta$ hCG-10 test provided a low accuracy (58.6\%).

The mean level of $\beta$-hCG in the vaginal fluid in a pregnancy with intact membranes varies throughout the pregnancy from $37.9 \mathrm{mUI} / \mathrm{mL}$ in the first trimester to $9.5 \mathrm{mUI} / \mathrm{mL}$ in the second trimester, and from 6.3 to $7.71 \mathrm{mUI} / \mathrm{mL}$ in the third trimester. On the other hand, the $\beta$-hCG levels in pregnancies with PROM in the literature ranges from 330.88 to $468.06 \mathrm{mUI} / \mathrm{mL}^{1,11,14}$

Due to the variation in $\beta$-hCG levels during different trimesters, it is valid to argue that the accuracy of the parameters may vary throughout pregnancy. In the literature, few studies evaluated this fact, although when is done this analysis, the $\beta$-hCG provides better sensibility in second trimester, which suggest that it is an opportunity for this pregnancy period. ${ }^{3,10}$ Our data analysis did not discern the parameters for each trimester, so it is not possible to compare the data for every trimester. We suggest that future studies with bigger samples should perform this analysis.

Another PROM marker with easy access and excellent parameter is creatinine. The literature reports that creatinine 
is a better PROM marker than $\beta$-hCG, ${ }^{2,18}$ with an accuracy of $100 \%$. This information shows it is necessary to evaluate creatinine as another good PROM marker. ${ }^{15}$

The hCG test should not be performed in the presence of blood, because vaginal bleeding can lead to false positive results due to the high hCG concentration in the blood. ${ }^{8}$ Thus, a false positive PROM result can lead to unnecessary interventions, such as hospitalization, antibiotic therapy, corticosteroid therapy and labor induction. 2,17

Therefore, it is important to keep searching for the ideal PROM maker, which is present in the amniotic fluid, has a long half-life, and can be detected throughout pregnancy. The test quality should not depend on the presence of blood, urine, feces, semen or others topic products that may be present in the vaginal fluid. ${ }^{5,7}$ Moreover, an ideal biomarker should provide a high concentration of amniotic fluid, low blood concentration, and an extremely low concentration in the vaginal fluid in pregnancies with intact fetal membranes. ${ }^{5}$ Many markers have been studied, and the $\beta$-hCG is among the most simple, easy to use, and cheap. ${ }^{14}$ Thus, the $\beta$-hCG test may be a practicable possibility for the diagnosis of PROM, although more studies are needed on its efficacy, and a consensus must be reached on the ideal cut-off points for the different trimesters. The description of several cut-off points may be explained by the difference in the sample size of the studies and the different inclusion and exclusion criteria.

The present study does not aim to set a definitive cut-off point; its goal is to evaluate the pregnancy test used for the diagnosis of PROM. In light of the aforementioned data, the $\beta$-hCG may be a practicable possibility for the diagnosis of PROM because it is a simple and fast exam that can be performed without any sophisticated equipment. This study can help health care managers make decisions to implement improvements in health care policies for the promotion of health and the prevention of diseases in women.

\section{Conflicts of Interest}

The authors have no conflicts of interest to disclose.

\section{Acknowledgment}

We would like to thank Fundação Araucária, which contributed with financial resources, and is an important foundation that promotes research in the state of Paraná, Brazil.

\section{References}

1 Kariman N, Hedayati M, Taheri Z, Fallahian M, Salehpoor S, Alavi Majd SH. Comparison of ELISA and three rapid HCG dipsticks in diagnosis of premature rupture of membranes. Iran Red Crescent Med J 2011;13(06):415-419
2 Tigga M, Malik S. Various biomarkers in diagnosing premature rupture of membranes: a cost effective analysis. Internet J Gynecol Obstet. 2014;19(01):1-6

3 Caughey AB, Robinson JN, Norwitz ER. Contemporary diagnosis and management of preterm premature rupture of membranes. Rev Obstet Gynecol 2008;1(01):11-22

4 Temel O, Cöğendez E, Selçuk S, Asoğlu MR, Kaya E. $\beta$-human chorionic gonadotropin assay in vaginal washing fluid for the accurate diagnosis of premature rupture of membranes during late pregnancy. J Turk Ger Gynecol Assoc 2013;14(04):201-204

5 El-Messidi A, Cameron A. Diagnosis of premature rupture of membranes: inspiration from the past and insights for the future. J Obstet Gynaecol Can 2010;32(06):561-569

6 Eskicioglu F, Gur EB. Diagnostic modalities in premature rupture of membranes. Int J Womens Health Reprod Sci. 2015;3(02):89-92

7 Marcellin L, Goffinet F. Are biological markers relevant for the diagnosis and the prognosis of preterm premature rupture of membranes (PPROM)? Clin Chem Lab Med 2012;50(06):1015-1019

8 Movahed F, Elmizadeh K, Javadi A, Choopani A. The value of qualitative detection of human chorionic gonadotropin in vaginal washing fluid for diagnosis of preterm premature rupture of membranes. Pak J Med Sci 2012;28(05):900-903

9 Cooper AL, Vermillion ST, Soper DE. Qualitative human chorionicgonadotropin testing of cervicovaginal washings for the detection of preterm premature rupture of membranes. Am J Obstet Gynecol 2004;191(02):593-596, discussion 596-597

10 Esim E, Turan C, Unal O, Dansuk R, Cengizglu B. Diagnosis of premature rupture of membranes by identification of beta-HCG in vaginal washing fluid. Eur J Obstet Gynecol Reprod Biol 2003; 107(01):37-40

11 Anai T, Tanaka Y, Hirota Y, Miyakawa I. Vaginal fluid hCG levels for detecting premature rupture of membranes. Obstet Gynecol 1997;89(02):261-264

12 Carranza Lira S, Negrete López M, Quinzaños Fresnedo C, Leaños Miranda A. [Usefulness of the qualitative detection of hCG in cervicovaginal lavage for the diagnosis of premature rupture of membranes]. Ginecol Obstet Mex 2009;77(03):142-146 Spanish

13 Tigga MP, Malik S. Comparative analysis of four biomarkers in diagnosing premature rupture of membranes and their correlation with onset of labour. Int J Reprod Contracept Obstet Gynecol 2015;4(04):1070-1075

14 Bahasadri S, Kashanian M, Khalili S. Evaluation of vaginal fluid $\beta$ human chorionic gonadotrophin for the diagnosis of preterm premature rupture of membranes. J Obstet Gynaecol Res 2013;39 (04):777-782

15 Mohamed RS, Rashed RM, Hassanein RA, Oun AR, Abdel-Maksoud SM. Vaginal fluid creatinine versus human chorionic gonadotropin for diagnosis of premature rupture of membranes. J Am Sci 2015;11(01):33-39

16 Kim YH, Park YW, Kwon HS, Kwon JY, Kim BJ. Vaginal fluid betahuman chorionic gonadotropin level in the diagnosis of premature rupture of membranes. Acta Obstet Gynecol Scand 2005;84 (08):802-805

17 El-Razik MA, Hegazy AE, El-Haseeb MA, Tawfeek M. Cervicovaginal fluid $\beta$-subunit human chorionic gonadotrophin for diagnosis of preterm premature rupture of membranes. Med J Cairo Univ 2010;78(01):491-494

18 Osman OM, Elghazaly M. Can Vaginal Washing Fluid Urea, Creatinine and Qualitative $\beta$-hCG Diagnose Suspected Premature Rupture of Membranes? Open J Obstet Gynecol 2014;4:967-972 